\title{
Design and Development of Training System for Teaching on Shaft Furnace Mechatronics
}

\author{
Ye Sun*, Ren Chen, Zuoliang Zhang, Meng Li, Yan Liu, Mingxia Feng, Huishu Zhang and Yan Cui \\ Department of Metallurgy Engineering, Liaoning Institute of Science and Technology, 117004, Benxi, China \\ *Corresponding author
}

\begin{abstract}
Based on the practical teaching requirements of metallurgical engineering, a cold position training device on the shaft furnace was designed in line with actual production. The control system adopts the integrated control cabinet and its design of the training device is implemented by the PLC of Siemens S7-300 and the configuration software of Real Bridge. The control mode includes two kinds of modes, which are remote control and manual control. Through the development and use of the shaft furnace training devices, the teaching content can be visualized. This device has been put into use in colleges, and obtained the good training effect.
\end{abstract}

Keywords-shaft furnace; Mechantronics system; PLC control system

\section{INTRODUCTION}

Metallurgical engineering is a major of strong engineering practicality, which is needed to improve the comprehensive analysis and the ability to use in practice. However, the ferrous metallurgical production process is a continuous industrial processes, and the process parameters are not allowed to change in the actual production process. So students do not achieve good effects by factory practice. In addition, students can not have the opportunity to practice by themselves in the practical process by taking safety and other factors into consideration. And it leads theory teaching to divorce from practice work. To make up the deficiencies of practical teaching and promote understanding of the professional foundation knowledge and metallurgical processes as well as equipments for students, developing related equipment for metallurgical technology training, creating realistic production environment of metallurgy process, enhancing the understanding of ferrous metallurgy production process for students and the engineering practice and innovation ability, are the basis to ensure the quality of course teaching[1]. Thus, we developed some practice teaching models of metallurgical engineering and the shaft furnace training device is one of the series of teaching model.

\section{The Production Process Of The Shaft Furnace}

The materials into the shaft furnace are pellets, lump ore and flux (limestone and dolomite). In addition, a certain amount of coke must be added to avoid the bond of the ironcontaining material and maintain the sufficient permeability of the bed layer. The reducing gas with the temperature from $800^{\circ} \mathrm{C}$ to $850^{\circ} \mathrm{C}$ is blown into the shaft furnace through the bustle pipe in the bottom of the shaft furnace. The gas flows to the top of the shaft furnace and the exhausted temperature from $250^{\circ} \mathrm{C}$ to $300^{\circ} \mathrm{C}$. The iron-containing material in the shaft furnace will be reduced to DRI (Direct reduced iron) with the metallization rate of seventy percentage to ninety percentage. The DRI and flux are added into the melter gasifier from the shaft furnace by a spiral feeder.

\section{The Shaft Furnace Training Device}

The cold state experimental model of semi-circle prereduction shaft furnace is produced according to a 1:20 ratio of the actual shaft furnace shown in Figure I. The experimental system mainly includes a cold state physical simulated test equipment of the pre-reduction furnace, pressure measurement devices and data collection device. The physical experimental device is composed of a cold state model, an air compressor, a flow control component and burden. The air compressed by the air compressor is supplied into the confining tube through the distributor and the flow control device and then into the cold state model. The burden is added from the spout on the top of the model and is discharged from the discharged pipe by the spiral feeder. And the discharged speed of the burden is controlled by the spiral feeder, which connected to the discharged pipe. The burden will be discharged into the closed bins to avoid the gas leak.

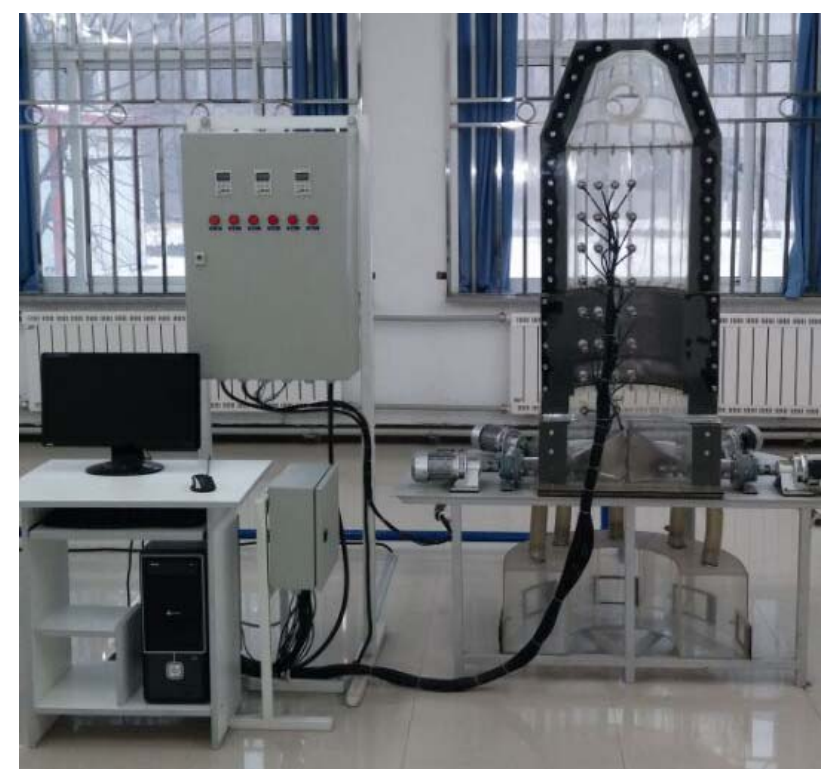

FIGURE I TRAINING DEVICE OF THE SHAFT FURNACE PROCESS 


\section{Control System Of The Training System}

The control system uses mechatronics control cabinet, in which the computer system, frequency converter, PLC, circuit breakers and contactors are mounted. The control buttons are installed in the faceplate of the control cabinet. The computer's serial ports are connected to the PLC's MPI interface via the connecting cable.

The control mode includes two modes, remote manual control and local manual control. The remote manual control is operated by the operator via the HMI operator interface. The local manual control is operated by the buttons in the control box to control all the motors and valves on the scene.

The ECI control system is integrated modular unit of four layers. There are indicator lights of fault display corresponding to each motor in the front of the control carbinet. There are a total control and data displayer in the bottom of the indicator lights. There is a keyboard which can be pulled out below the displayer. When you perform an experiment, you should make sure all the circuit breakers in the carbinet are closed firstly, then connect to the external power and open the circuit breakers sequentially from left to right and from top to bottom lastly. If there is no exception appeared, the power indicator light will work. When the display screen is in normal standby state and there is no alarm and fault indication each part, the experiment can be carried out.

\section{Software Design Of The Training System}

The design adopts cost-effective homemade Real Bridge configuration software, which will be combined with PLC control system for secondary development. The configuration design can complete the remote manual of the entile production process, while the data can be collected and managed in real time. All operations can be completed by the pulled keyboard below the display screen and the built-in touchpad mouse. There are the operating virtual buttons of all components of the system and the corresponding striking indication in the display screen. When clicking on the device of the corresponding portion, it can be run according to our requirements. The production process and equipment operating parameters of the blast furnace of the whole process of the production line can display in the blast furnace process flow diagram, main screen of the blast furnace system, motor control system screen, flow detection system screen and pressure detection system screen. Parameters of the production process can be modified in the corresponding parts of the screen through the keyboard. All the collected and operational data during the experiment will be recorded in real time by the mouse and keyboard. The data can be saved in any location of the hard disc. Figure II is the main interface of the shaft furnace training system. Figure III is the control interface of the data collection and run tendency system of the shaft furnace. Figure IV is the control interface of the inquiry system of the data collection of the shaft furnace. Figure $\mathrm{V}$ is the control interface of the grouping drawing system of the data collection of the shaft furnace.

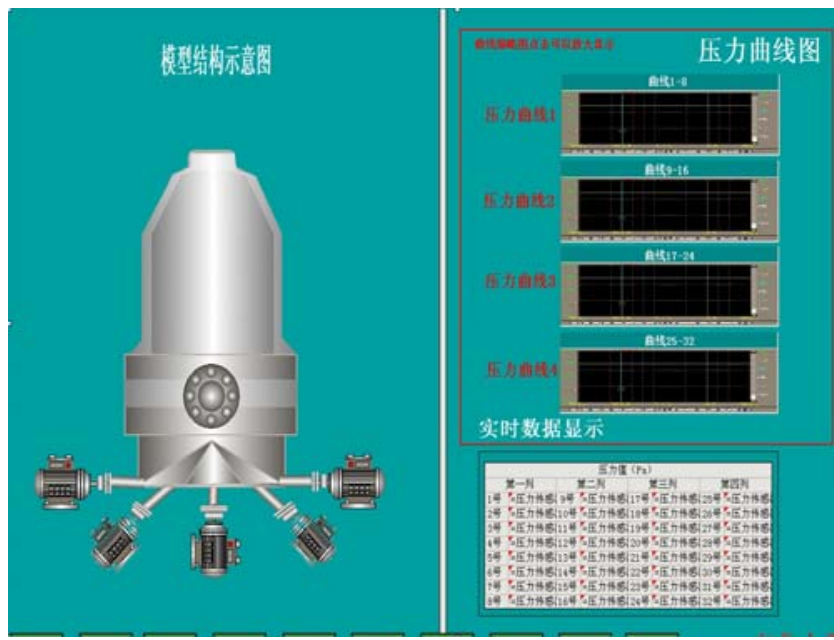

FIGURE II MAIN INTERFACE OF THE SHAFT FURNACE TRAINING SYSTEM

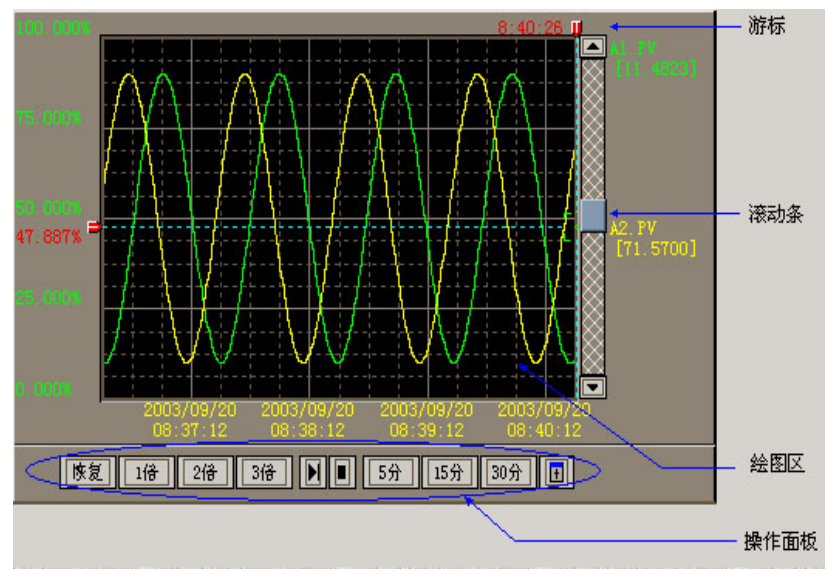

FIGURE III CONTROL INTERFACE OF THE DATA COLLECTION AND RUN TENDENCY SYSTEM OF THE SHAFT FURNACE

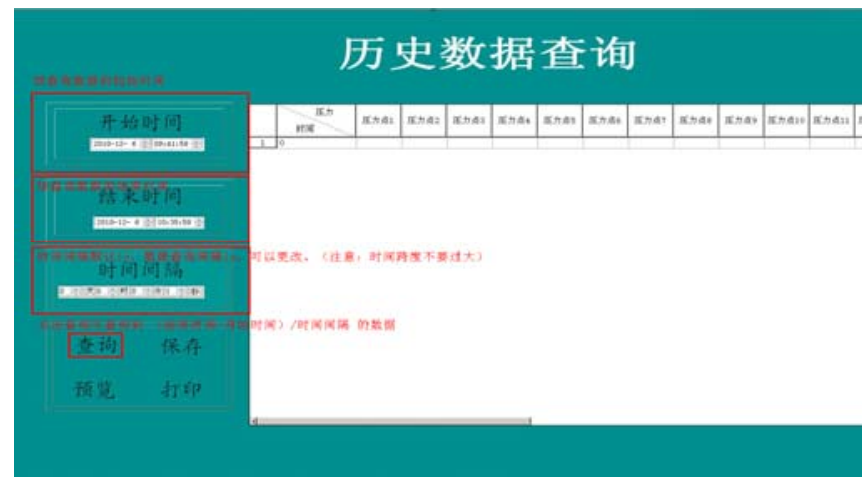

FIGURE IV THE CONTROL INTERFACE OF THE INQUIRY SYSTEM OF THE DATA COLLECTION OF THE SHAFT FURNACE 


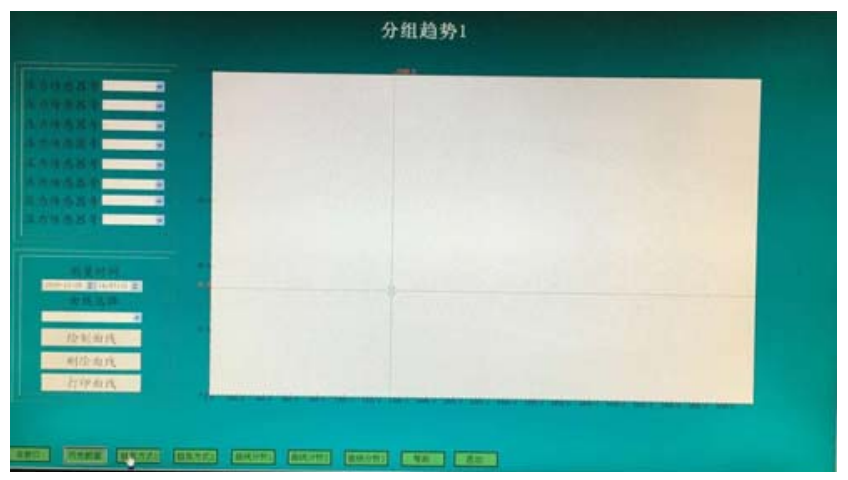

FIGURE V THE CONTROL INTERFACE OF THE GROUPING DRAWING SYSTEM OF THE DATA COLLECTION OF THE SHAFT FURNACE

\section{CONCLUSIONS}

Through the development and use of the shaft furnace training devices, the teaching content can be visualized and the distance between the classroom and the practice can be narrowed. This device has been put into use for one year, and obtains the good teaching effect. The system has the following characteristics in practical teaching:

(1) Applicability: The practical teaching system with its intuitive form can make students fully understand the production process and improve the timeliness of the teaching. The deficiencies of the field work which is allowed to see and not to try can be made up by establishing realistic simulation environment.

(2) Comprehensiveness: Practical teaching system with computer modeling technique, powder-jet technology, mechanical transmission, motor drive technology and pneumatic conveying technology can achieve the integrated practice teaching of ferrous metallurgy process and operation, sensor, pneumatic technology, PLC control technology, electrical control system, mechanical system installation, motor drive technology, system maintenance, fault detection technology and configuration monitoring technology.

(3) Flexibility: Practical teaching system can fit ferrous metallurgy, mechanics, automation, computer and other majors, which can meet the requirements of the practice training segment of understanding practice, production practice and graduation practice for students. Therefore, there is strong flexibility and more widely adaptability. On the other hand, not only the test can be appointed at any time, but also the impact on production by the operating conditions and the program changes can be experienced in the training process. It can enable students to deepen the understanding of the practice knowledge.

(4) Security: Because of the complexity of the iron and steel metallurgy production process and the high degree of the continuity, there are security risks at any time and anywhere. Students will inevitably face security problems when they enter the site to study and practice. Practice teaching system provides a secure platform for teachers and students to learn and practice. Teaching tasks can be completed in a more relaxed environment.

(5) Practicability: Metallurgical engineering graduates, who are cultivated by the existing teaching mode, have poor perceptual knowledge for actual operation. So the factories often take a lot of time, effort and cost to retrain them. However, it makes teaching follow by the actual production by using practical teaching system to enable students to conduct necessary training operation to obtain practical skills.

\section{ACKNOWLEDGMENT}

The research funded by Liaoning Province Education Administration (No.L2014506) and Doctor Startup Fund of Liaoning Institute of Science and Technology (No.1406B12) and Education Project of Liaoning Institute of Science and Technology.

\section{REFERENCES}

[1] X. G. Wang, J. F. Liu, J. G. Lu, "Design and realization of control system for heat transfer training device," Automation \& Instrumentation, vol. 12,2000 , pp. 37-41 